\title{
Convectively-coupled High-frequency waves triggered Kerala floods in 2018 and 2019
}

KIRAN S R ( $\sim$ kiransreekumarr@gmail.com )

Central Polytechnic College, Thiruvananthapuram, Kerala, India https://orcid.org/0000-0003-32008624

\section{Research Article}

Keywords: Kerala Floods, Indian Monsoon, Modes of Variability, Equatorially-trapped waves

Posted Date: June 1st, 2021

DOl: https://doi.org/10.21203/rs.3.rs-574169/v1

License: (9) This work is licensed under a Creative Commons Attribution 4.0 International License. Read Full License

Version of Record: A version of this preprint was published at Journal of Extreme Events on July 3rd, 2021. See the published version at https://doi.org/10.1142/S2345737621500147. 


\title{
Convectively-coupled High-frequency waves triggered Kerala floods in 2018 and 2019
}

\author{
Kiran S. R. \\ Department of Civil Engineering \\ Central Polytechnic College \\ Thiruvananthapuram, Kerala \\ Email: kiransreekumarr@gmail.com \\ ORCID Id: 0000-0003-3200-8624
}

\begin{abstract}
Floods have repeatedly battered the South Indian state, Kerala, as a result of extremely anomalous rainfall during Boreal Summers, since 2018. Previous studies have seldom adopted a systematic approach to understand the phenomenon responsible for the extreme events. Hence, this study intends to identify this dynamical phenomenon based on spectral methods, and attempts to render a preliminary solution to the problem. The study exposes the presence of westward-propagating highfrequency tropical atmospheric waves of 5-8 days period, which originated from east Indian Ocean or West Pacific and headed towards the east coast of Africa. The wave troughs ensured sufficient moisture availability along its path, causing extreme precipitation over Kerala on the way.

Index Terms-Kerala Floods, Indian Monsoon, Modes of Variability, Equatorially-trapped waves
\end{abstract}

\section{INTRODUCTION}

Kerala, the south-west coastal state of India, experienced heavy rainfall and consequent floods in the years 2018 and 2019 during Summer. The state received extremely heavy rainfall during the South-West Monsoon in the two years - from $8^{\text {th }}$ to $17^{\text {th }}$ August 2018 and from $3^{\text {rd }}$ to $10^{\text {th }}$ August 2019, which caused unprecedented floods resulting in massive loss of life and property. These recurrent extreme events in the state have raised questions of changing climate in the southern part of Peninsular India. Hence, there arose a necessity to document the observations and analyse the physical phenomenon responsible for the disaster.

Vimal and Harsh (2019) observed no increase in mean and extreme precipitation in Kerala over the past six decades and identified that the extreme rainfall event in August 2018 was driven by anomalous atmospheric conditions due to climate variability rather than anthropogenic factors [1]. Hunt and Menon (2020) concluded that the precipitation in Kerala may be $18 \%$ heavier for the pre-industrial period and $36 \%$ heavier for a prospective climate in 2100 [2]. According to Ref. [3], the presence of a strong westerly jet along with the formation of the offshore vortex trough and the transport of mid-tropospheric moisture from various sources under the presence of conducive vertical shear of horizontal wind may have contributed to the extreme rainfall over Kerala in 2018. Further, there are theories that the strong westerly flow, which is a part of the cross equatorial Monsoon flow, was constantly propelled by a couple of cyclonic systems over Bay of Bengal,
South China Sea and West Pacific [4]. Similarly, Ref. [5] deduced that the Kerala floods of 2018 was triggered by the formation of an intense and long-duration atmospheric river with more than $60 \%$ of moisture supply from the CentralEastern Indian Ocean.

Although, the above studies attempted to investigate the extreme precipitation in 2018 from the general wind field conditions existed then, no conclusive evidences to support their theories exist hitherto, even after the extreme events repeated in 2019 and 2020 during the same season. Especially in the context of recurrence of extreme events in the state, there exist a dire need for a systematic investigation of this phenomenon, which becomes the prime motivation for this study.

\section{DATA \& METhodology}

The daily gridded rainfall data (in millimetres) over Kerala at a spatial resolution of $0.25^{\circ} \times 0.25^{\circ}$, for the period from 2011 to 2019, is obtained from Indian Meteorological Department (IMD) [6]. The globally gridded daily mean data of zonal and meridional winds at a spatial resolution of $0.25^{\circ} \times 0.25^{\circ}$ from 2011 to 2018 is obtained from ERA5 Reanalysis, the fifth generation European Centre for Medium-Range Weather Forecasts (ECMWF) reanalysis for global climate. This gives the specific humidity $(\mathrm{kg} / \mathrm{kg})$ and horizontal wind (zonal and meridional) data (in metres per second) for different vertical pressure levels, ranging from 1000 to 100 hecto pascals.

In this study, the daily departures from the mean of atmospheric variables during 2018 and 2019 are determined to analyze the cause of anomalous precipitation over the Southern Indian state. This is estimated by deducting the average of daily data of the atmospheric variables from 2011 to 2017 (7year daily mean) from the daily data for the years 2018 and 2019 separately. Hovmöller diagrams, which depict the temporal variation of atmospheric parameters along zonal direction, are used to identify and explain the propagation of atmospheric waves and its characteristics. Fast Fourier Transform (FFT) is performed on time series of atmospheric variables or its anomalies for the ease of representation in frequency domain. The dominant harmonics, thus identified, are filtered out using Band-Pass Filters (BPF) for further analysis. 


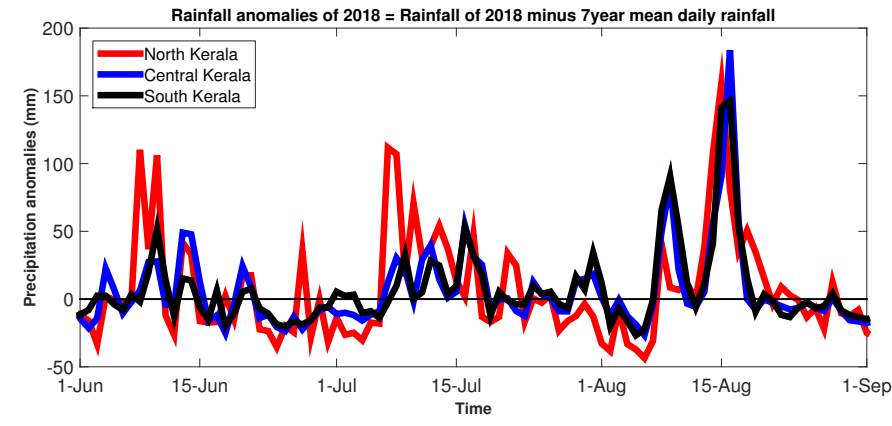

Fig. 1. IMD daily rainfall anomalies (in millimetres) of 2018 over North, Central and South Kerala, measured with respect to the 7 year mean precipitation.

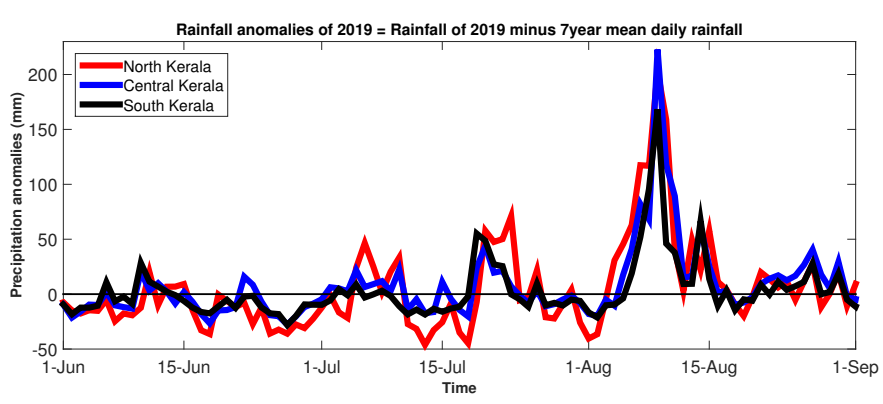

Fig. 2. IMD daily rainfall anomalies (in millimetres) of 2019 over North, Central and South Kerala, measured with respect to 7 year mean precipitation.

\section{RESUlTS \& Discussions}

\section{A. Rainfall over Kerala in 2018 \& 2019}

Floods in the state of Kerala in 2018 and 2019 were the result of intense precipitation during the South-West Monsoon from June to August. The excess rainfall for the years is quantified by subtracting the mean daily precipitation for 7 years (2011 to 2017) from the actual daily precipitation for the respective years. The rainfall anomalies, thus determined for the North, Central and South Kerala, for the years 2018 and 2019 are shown in Fig. 1 and Fig. 2 respectively.

In 2018, North Kerala received highly anomalous rainfall of the order of $100 \mathrm{~mm}$, during the months of June, July and August (Fig. 1). Compared to the other regions, the Northern part of Kerala is observed to be very sensitive to the deviant precipitation trends. It received over $100 \mathrm{~mm}$ of excess rainfall during the first half of June and July. In August, the Monsoon rainfall touched its seasonal high, with two distinct peaks in precipitation anomalies about $-8^{\text {th }}$ August $(100 \mathrm{~mm})$ and $15^{\text {th }}$ August $(180 \mathrm{~mm})$. Hence, this shall be deemed an extreme event in the forthcoming discussions.

The year 2019 also witnessed a similar anomalous rainfall trend, especially in the month of August (Fig. 2). On $8^{\text {th }}$ August, Kerala received an exceptional rainfall anomaly of $220 \mathrm{~mm}$. As observed in 2018, the northern part of the state experienced the wrath of the extreme event relatively.

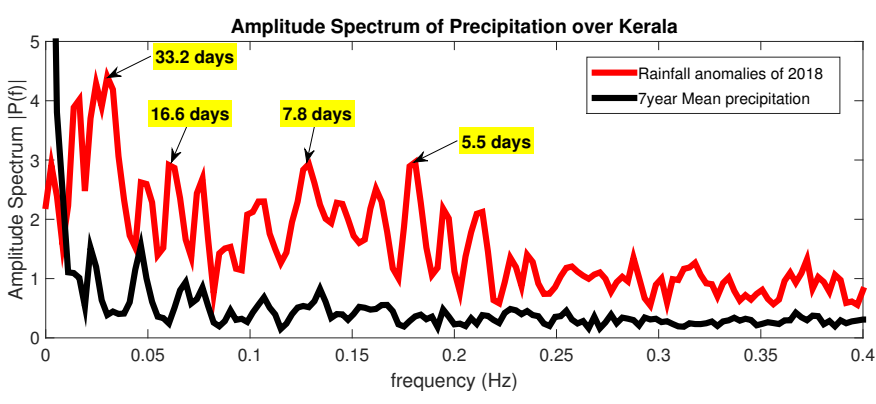

Fig. 3. Amplitude spectrum of IMD rainfall anomalies of 2018 averaged over the state of Kerala, in comparison to that of the 7 year mean precipitation.

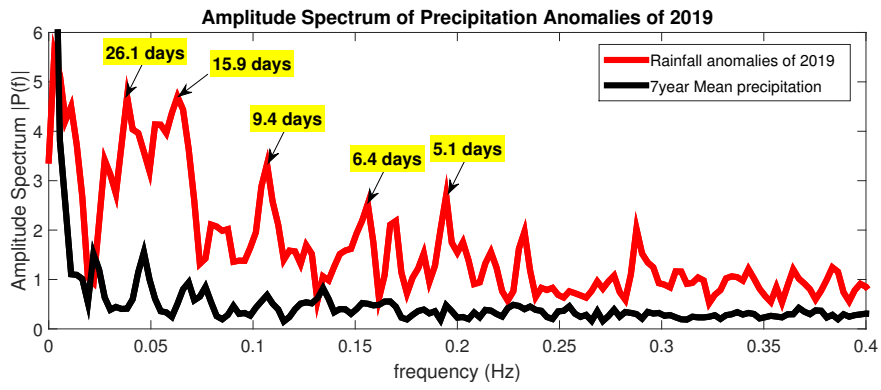

Fig. 4. Amplitude spectrum of IMD rainfall anomalies of 2019 averaged over the state of Kerala, in comparison to that of the 7 year mean precipitation.

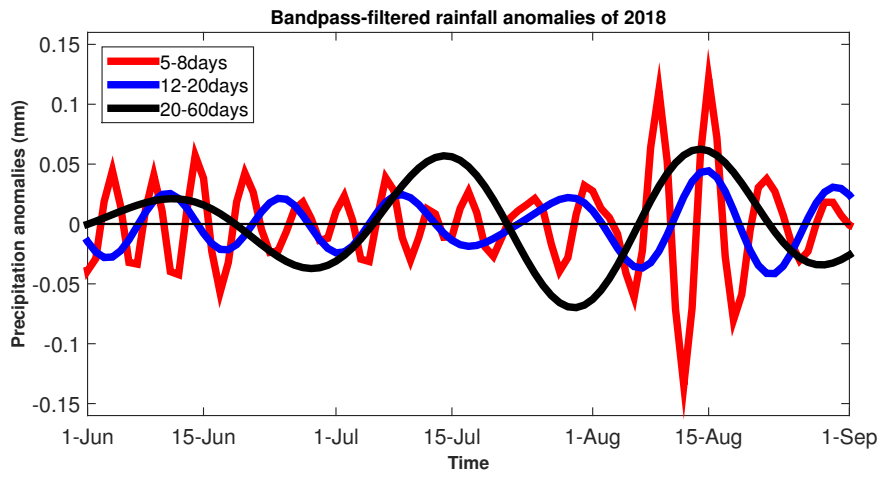

Fig. 5. 5-8days, 12-20days and 20-60days bandpass-filtered IMD rainfall anomalies of 2018 averaged over the state of Kerala.

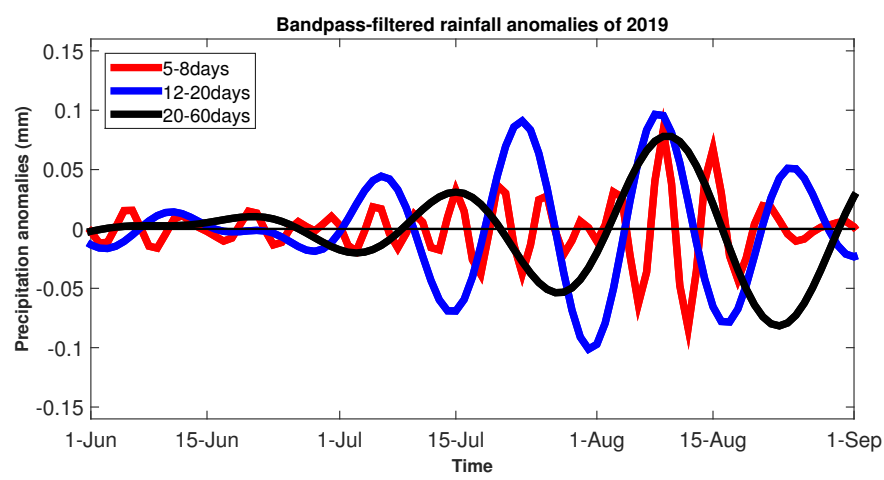

Fig. 6. 5-8days, 12-20days and 20-60days bandpass-filtered IMD rainfall anomalies of 2019 averaged over the state of Kerala. 


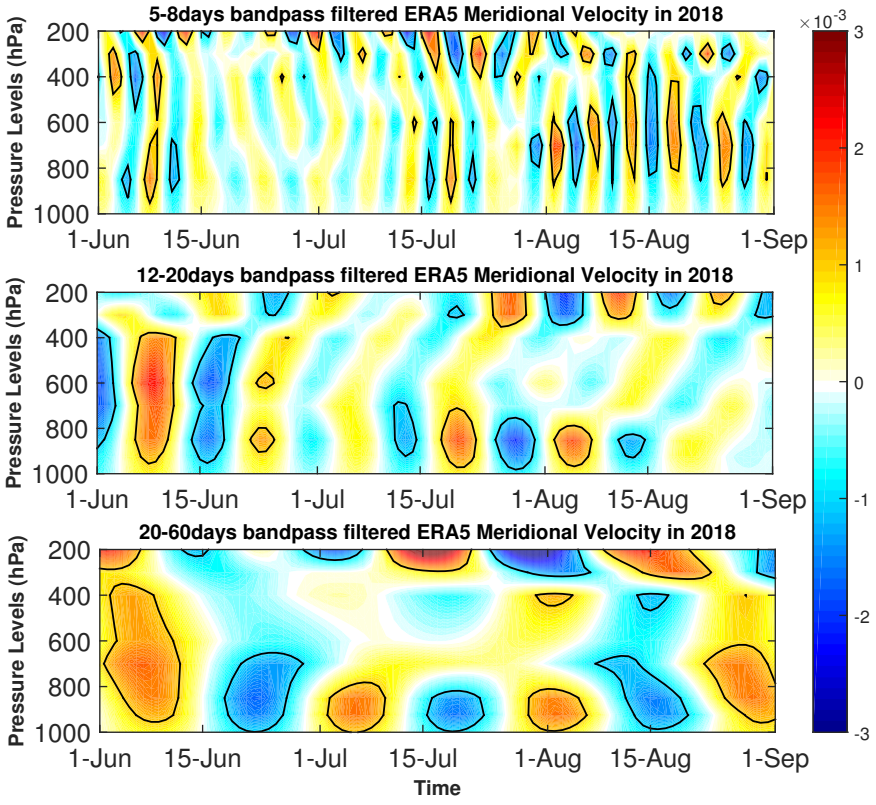

Fig. 7. 5-8days, 12-20days and 20-60days bandpass-filtered ERA5 Meridional velocities of 2018 averaged over the state of Kerala with altitude.

\section{B. Dominant modes of variability}

It is always ideal to look into the constituent harmonics, which contributed to the precipitation anomalies of 2018 and 2019. Hence, Fast Fourier Transforms (FFT) of the spatiallyaveraged rainfall anomalies is performed for both the years, and the resultant amplitude spectrum are shown in Fig. 3 and Fig. 4. The spectrum corresponding to the 7 year mean daily rainfall is superimposed for comparison. In 2018, substantial spectral density is confined to frequency bands which peak at 5.5, 7.8, 16.6 and 33.2 days. In comparison to the mean daily precipitation, it possessed higher amplitude, except for semi-annual mode (180 days). Similarly, the frequency bands of peak amplitude corresponds to 5.1, 6.4, 9.4, 15.9 and 26.1 days for the rainfall of 2019. The semi-annual variability, a characteristic response of the equatorial Indian Ocean region during Spring and Fall [7], can be neglected for this study. Therefore, the dominant periods of variability are chosen as 5-8 days, 12-20 days and 20-60 days. The harmonic corresponding to 9.4 days in 2019 is not considered for analysis, as it is found to be of lesser significance.

For further analysis, the time series of precipitation anomalies for the concerned years are filtered separately for the bands 5-8 days, 12-20 days and 20-60 days. Fig. 5 shows the bandpass-filtered rainfall anomalies for the year 2018. The 5-8 days high frequency mode made an exceptional contribution to the extreme event in August, compared to the other two modes. The high frequency mode rightly captured the two prominent peaks in rainfall departures during the first half of the month. In 2019, the extreme precipitation which peaked on $8^{\text {th }}$ August was the unambiguous consequence of

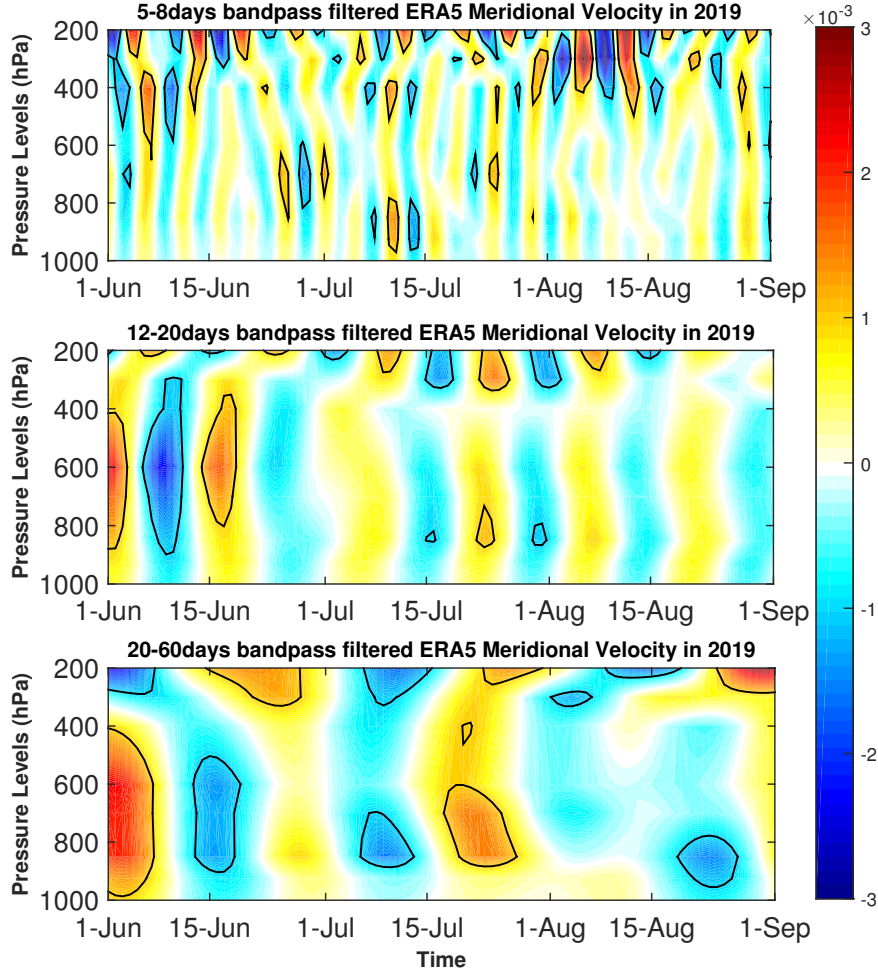

Fig. 8. 5-8days, 12-20days and 20-60days bandpass-filtered ERA5 Meridional velocities of 2019 averaged over the state of Kerala with altitude.

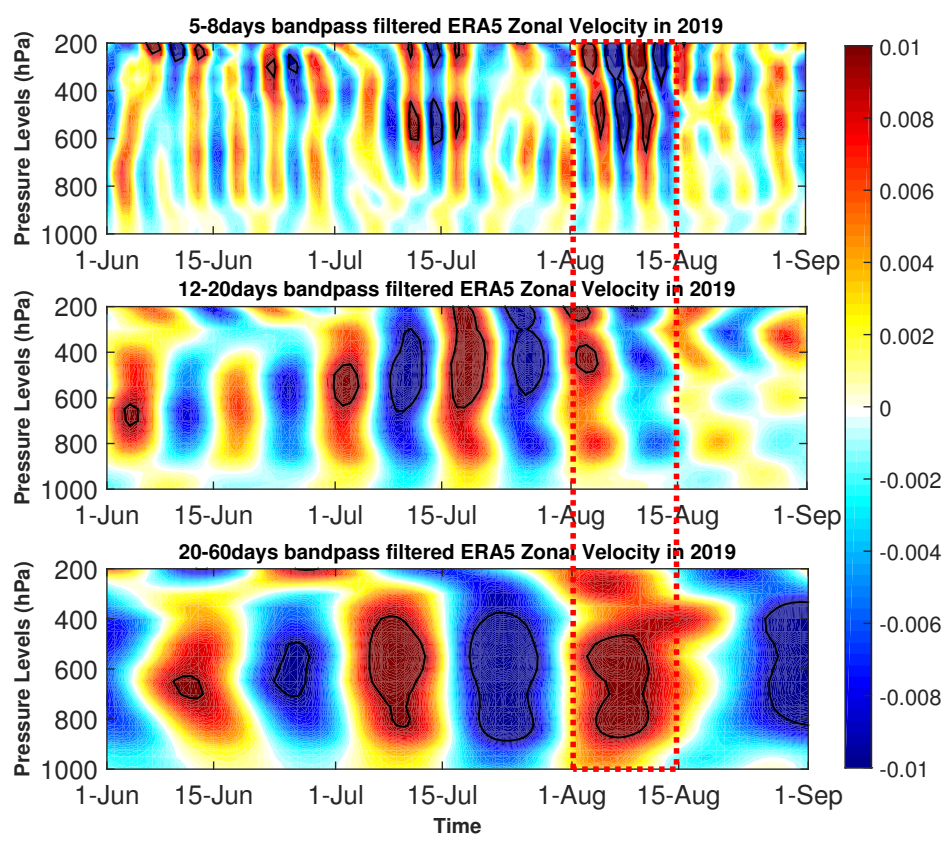

Fig. 9. 5-8days, 12-20days and 20-60days bandpass-filtered ERA5 Zonal velocities of 2019 averaged over the state of Kerala with altitude. The period of extreme event is shown inside the red-coloured dashed box. 

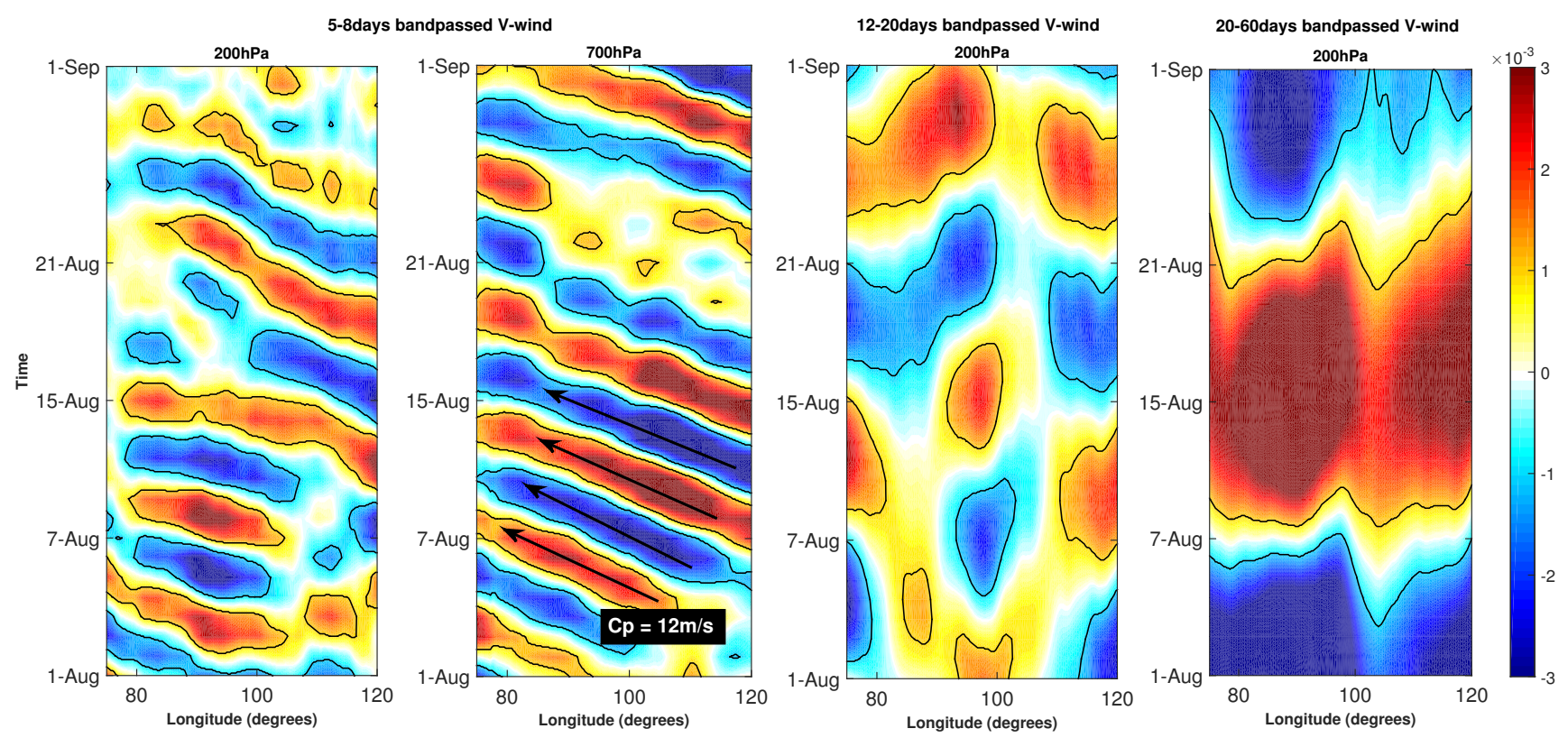

Fig. 10. (first \& second figure) 5-8 days bandpass-filtered ERA5 Meridional velocities of August 2018 meridionally averaged over the state of Kerala at pressure levels $200 \mathrm{hPa}$ and $700 \mathrm{hPa}$ respectively. (third figure) 12-20 days bandpass-filtered Meridional velocities at 200hPa in 2018. (fourth figure) 20-60 days bandpass-filtered Meridional velocities at $200 \mathrm{hPa}$ in 2018 .

superposition of all the three modes in-phase (Fig. 6). Yet, the 5-8 days periodicity leads to render the sharpness of the precipitation curve. Hence, it is important to investigate the phenomenon which is responsible for these dominant modes of variability, especially the high frequency mode, which have assumed great significance to the extreme rainfall events of 2018 and 2019.

ERA5 Reanalysis meridional winds over the state of Kerala, for different pressure levels in 2018 and 2019, are bandpassfiltered for the dominant modes of variabilty (Fig. 7 and Fig. 8). In 2018, the 5-8 days mode is associated with the intensification of meridional winds at mid-troposphere $(800 \mathrm{hPa}-600 \mathrm{hPa})$ which extends upto upper atmosphere (near $200 \mathrm{hPa}$ ), during the extreme event in August (Fig. 7). Similar anomalous wind patterns are seldom observed for the other modes at $700 \mathrm{hPa}$ level; although these had modulated the upper troposphere, but not exclusive to period of extreme rainfall. Hence, the role of the high frequency mode in causing the Kerala floods of 2018 stands substantiated, as it conforms to the anomalous precipitation behaviour observed in Fig. 5.

On the other hand, during the extreme event in August 2019, a stark variability in winds at upper atmosphere $(400 \mathrm{hPa}-$ $200 \mathrm{hPa}$ ) is observed for the 5-8 days periodicity (Fig. 8). Other modes possessed relatively lower magnitudes at any levels during this period, although all the three modes contributed comparably to the precipitation anomalies as per Fig. 6 . Therefore, the modes of period 12-20 days and 20-60 days are totally absent in the meridional winds, although they were prominent in the 2019 rainfall. But, these modes can be observed to constitute the zonal winds over Kerala (Fig. 9), which are long deemed classical Intra-seasonal Oscillation (ISO) modes associated with the zonal component of the Monsoon Jet [11, 13]. As a consequence, it can be inferred that the Quasibiweekly Oscillations (QBO) of 12-20 days period and the Madden-Julian Oscillations (MJO) of 20-60 days period might have exacerbated the extreme event in August 2019 [12], in addition to the high frequency mode (note that the 5-8 days mode had even dominated the zonal winds in the upper atmosphere (Fig. 9)). On the contrary, QBO and MJO cannot drive the anomalous event by itself. Hence, the high frequency mode is unequivocally considered as the causative factor for extreme precipitation in the state, which manifested at midtroposphere in 2018 and at upper atmosphere in 2019.

\section{Westward-propagating High-frequency Waves}

In order to study the temporal evolution of the filtered meridional winds at any pressure levels, Hovemöller diagrams are prepared for the month of August by meridional averaging over the latitudinal extend of the state of Kerala. As per the above discussion, the middle and higher levels of troposphere resonated to the 5-8 days mode during the extreme event of 2018 , while only the upper atmosphere resonated to 12 20 days and 20-60 days periodicity during the same event. Therefore, Hovemöller diagram corresponding to $700 \mathrm{hPa}$ is prepared only for the most dominant high frequency mode, while it is prepared at $200 \mathrm{hPa}$ for all the three modes of variability (Fig. 10). The 5-8 days mode at $700 \mathrm{hPa}$ exposes a interesting dynamical phenomenon, vide Fig. 10(second figure). During the extreme event of August 2018, signals of strong anomalous meridional winds propagated from the east equatorial Indian Ocean or the West equatorial Pacific $\left(100^{\circ} \mathrm{E}\right.$ $\left.-120^{\circ} \mathrm{E}\right)$ to the east coast of Africa, with the phase speed $\left(C_{p}\right)$ 

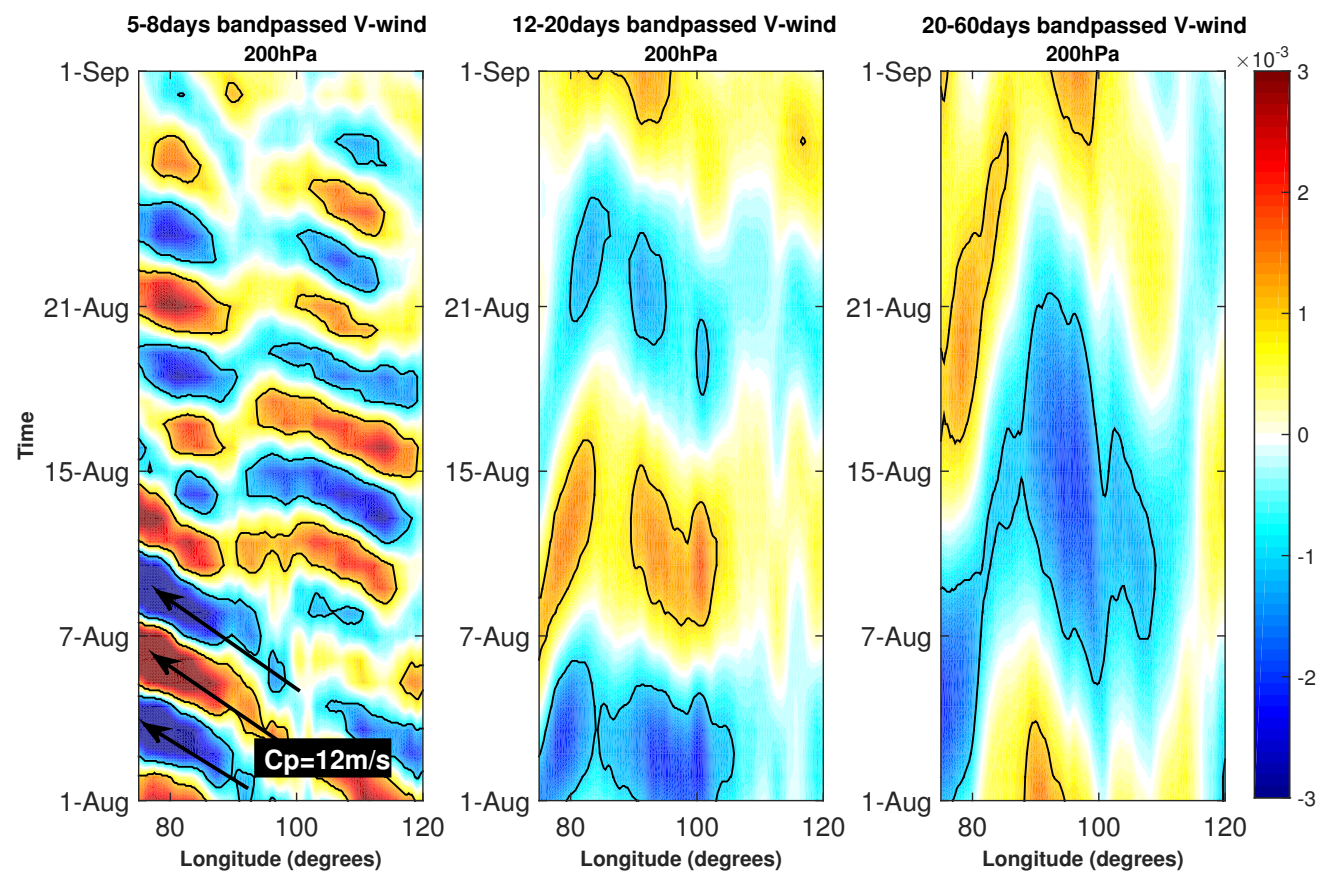

Fig. 11. (first figure) 5-8 days bandpass-filtered ERA5 Meridional velocities of August 2019 averaged meridionally over the state of Kerala at $200 \mathrm{hPa}$ pressure level. (second figure) 12-20 days bandpass-filtered Meridional velocities at 200hPa in 2019. (third figure) 20-60 days bandpass-filtered Meridional velocities at $200 \mathrm{hPa}$ in 2019 .

of about $12 \mathrm{~m} / \mathrm{s}$. These westward propagating signals possess wave characteristics which resemble the equatorially trapped atmospheric waves of synoptic time scales [8-10]. Although these waves appeared predominantly at $700 \mathrm{hPa}$ level, their remnants may be found even at $200 \mathrm{hPa}$ (Fig. 10(first figure) and Fig. 7). The variability associated with meridional winds corresponding to $12-20$ days and $20-60$ days at $200 \mathrm{hPa}$, in Fig. 10(third figure) and Fig. 10(fourth figure) respectively, do not reveal any wave characteristics in the wind field.

Similarly, Hovemöller diagrams are prepared from meridional winds at $200 \mathrm{hPa}$ pressure level for the three variability modes, because only the upper atmosphere resonated to the high frequency mode in 2019 (Fig. 11). It is astonishing to observe the recurrence of westward propagating signals in the upper troposphere of 5-8 days period, as it coincide with floods which battered the South Indian state for the second consecutive year (Fig. 11(first figure)). The atmospheric waves which originated near the east Indian Ocean $\left(100^{\circ} \mathrm{E}\right)$ crossed over Kerala and finally reached Africa, with the same phase speed as in 2018. As anticipated, the other modes had not assumed significance during the extreme event (Fig. 11(second figure) and Fig. 11(third figure)).

The ERA5 specific humidity in the atmosphere is vertically integrated from near surface (1000 $\mathrm{hPa})$ to mid-troposphere $(600 \mathrm{hPa})$ and bandpass-filtered for the high-frequency mode for the year 2018, with the objective to identifying the mechanism responsible for the rainfall event(Fig. 12). The figure is overlaid with winds (5-8 days bandpassed) at $700 \mathrm{hPa}$. The westward-propagating high-frequency waves manifested as cyclonic and anti-cyclonic vortices in the mid-troposphere, trapped to the north of the equator. The cyclonic circulations, which are itself characteristic low-pressure centres fuelling convection, seems to have advected large quantity of moisture across the Indian Ocean basin, as observed in figure. Hence, these convectively-coupled wave troughs enhanced the availability of moisture in the region.

\section{Summary \& CONCLUSions}

Kerala experienced a spate of flood events in 2018 and 2019 during Summer Monsoon. This study resolves to understand the dynamics of anomalous rainfall events in the state and gives better insights from the available observations. The summary of analysis and the conclusions thus drawn are discussed here.

1) Extreme precipitation events recurred in Kerala in 2018 and 2019 during the month of August, with mean maximum daily anomaly of $180 \mathrm{~mm}$ and $220 \mathrm{~mm}$ respectively. Fourier Transforms performed on the precipitation anomalies exposed the prominent modes of variability 5 to 8 days, 12 to 16 days and 20 to 60 days. Out of these, the high frequency mode ( 5 to 8 days) is observed to dominate over the other two in 2018 during the extreme event, although all the three seemed to possess comparable magnitudes as they fell in-phase in 2019.

2) The spatially averaged meridional winds for different vertical levels of pressure reveal the dominant presence of the high frequency mode from middle to upper troposphere in 2018 as well as at the upper troposphere 


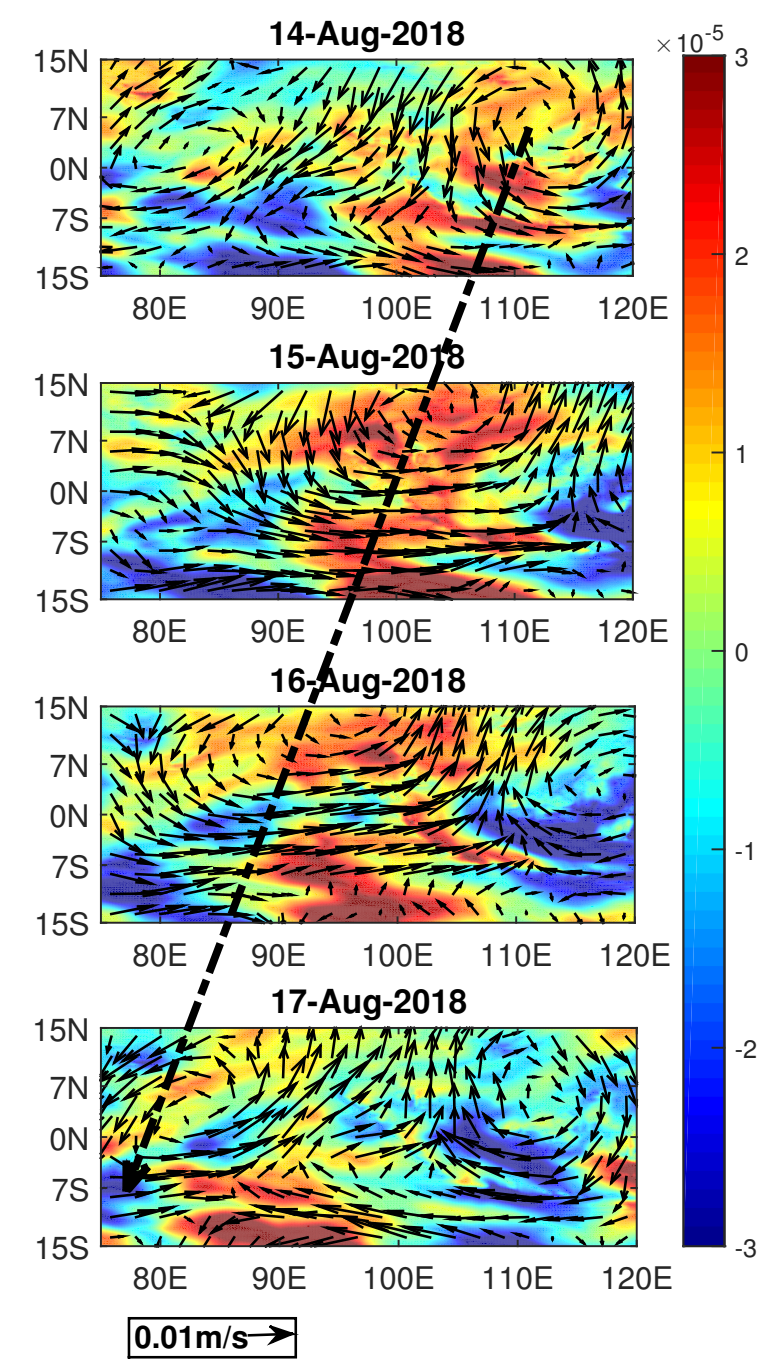

Fig. 12. 5-8days bandpass-filtered Specific humidity vertically integrated from surface $(1000 \mathrm{hPa})$ to $600 \mathrm{hPa}$ overlaid with 5-8days bandpass-filtered ERA5 winds at $700 \mathrm{hPa}$ from $14^{\text {th }}$ to $17^{\text {th }}$ August 2018 .

in 2019, all particular to the period of extreme events in the state. The 12-20 days mode (Quasi-biweekly Oscillation) and 20-60 days mode (Madden-Julian Oscillation) have characterized the zonal winds in 2019, thereby justifying their contribution to the extreme event of the year, but not exclusively. Hence, the 5-8 days high frequency mode is the sole factor responsible for the extreme precipitation in Kerala.

3) Hovemöller diagrams corresponding to the midtroposphere in 2018 and upper atmosphere in 2019 show the dominant presence of easterly signals of 5-8 days periodicity. These are westward-propagating high frequency tropical atmospheric waves of characteristic phase speed of nearly $12 \mathrm{~m} / \mathrm{s}$, which originate near east equatorial Indian Ocean or tropical West Pacific and travel to the east coast of Africa, and coincide with the same period of extreme rainfall events over Kerala. Moreover, the waves appeared as cyclonic (troughs) and anti-cyclonic (crests) circulations trapped to the north of equator. The wave troughs catalysed convection and ensured continuous supply of moisture along its trajectory. Therefore, the high frequency waves played a significant role in driving the recurrent anomalous precipitation in the South Indian state. The analysis of more characteristics of this wave, its structure and the thermodynamics of the problem shall be part of the future work.

\section{ACKNOWLEDGMENT}

The author thanks Asia-Pacific Data Research Center (APDRC) services for making available the ERA5 Reanalysis data free available online for all users.

\section{Author CONTRIBUtions}

K.S.R. performed the analysis, drawn conclusions and prepared the manuscript.

\section{COMPETING INTERESTS}

The author declares that there exist no competing interest with any person or agency in matters related to this research, and has not received any funds or grants in any form for the same.

\section{REFERENCES}

[1] Vimal Mishra and Harsh L. Shah, "Hydroclimatological perspective of the Kerala flood of 2018," J. Geo. Soc. India, vol. 92, 2019, pp. 645-650.

[2] M. R. Hunt and Arathy Menon. "The 2018 kerala floods: a climate change perspective," Cli. Dyn., vol.54, 2020, page 2433-2446.

[3] V. Yesubabu, C.V. Srinivas, Ghouse Basha, D. Hari Prasad, Sabique Langodan, M. Venkat Ratnam, and Ibrahim Hoteit, "A diagnostic study of extreme precipitation over Kerala during August 2018," Atm. Sci. Lett., 2019, pp. 1-26.

[4] Saji Mohandas, Timmy Francis, Vivek Singh, A. Jayakumar, John P. George, A. Sandeep, Prince Xavier, E.N. Rajagopal, "NWP perspective of the extreme precipitation and flood event in Kerala (India) during August 2018," Dyn. Atm Oce., vol. 91, 2020, pp. 1-21.

[5] Rosa Vellosa Lyngwa and Munir Ahmad Nayak, "Atmospheric river linked to extreme rainfall events over Kerala in August 2018," Atm. Res., vol. 253, 2021, pp. 1-13.

[6] Pai D.S., Latha Sridhar, Rajeevan M., Sreejith O.P., Satbhai N.S. and Mukhopadhyay B., "Development of a new high spatial resolution $\left(0.25^{\circ} \times 0.25^{\circ}\right)$ Long period (1901-2010) daily gridded rainfall data set over India and its comparison with existing data sets over the region," MAUSAM, vol. 65, 1, 2014, pp.1-18.

[7] K. Wyrtki, "An equatorial jet in the indian ocean. Science, vol. 181, 1973, pp. 262-264.

[8] Carlos F. M. Raupp and Pedro L. Silva Dias, "Excitation mechanism of mixed Rossby-Gravity waves in the equatorial atmosphere: Role of the nonlinear interactions among equatorial waves," J. of Atm. Sci., Vol. 62, 2005.

[9] Michael Dickinson and John Molinari, "Mixed Rossby-Gravity waves and western pacific tropical cyclogenesis. part i: Synoptic evolution," J. of Atm. Sci., Vol. 59, 2002.

[10] S. R. Kiran, "Understanding the Kerala Floods of 2018: Role of Mixed Rossby-Gravity Waves," unpublished.

[11] Xin Yan, Song Yang, Teng Wang, Eric D. Maloney, Shaorou Dong, Wei Wei and Shan He, "Quasi-biweekly oscillation of the Asian monsoon rainfall in late summer and autumn: different types of structure and propagation," Cli. Dyn., vol. 53, 2019, pp. 6611-6628.

[12] Raghu Murtugudde, Richard Seager, and Prasad Thoppil, "Arabian sea response to monsoon variation," Paleoceanography, Vol. 22, 2007.

[13] Sulochana Gadgil, "The monsoon system: Land-sea breeze or the ITCZ?,” J. Earth Syst. Sci., vol. 127, 2018, pp. 1-29. 
Figures

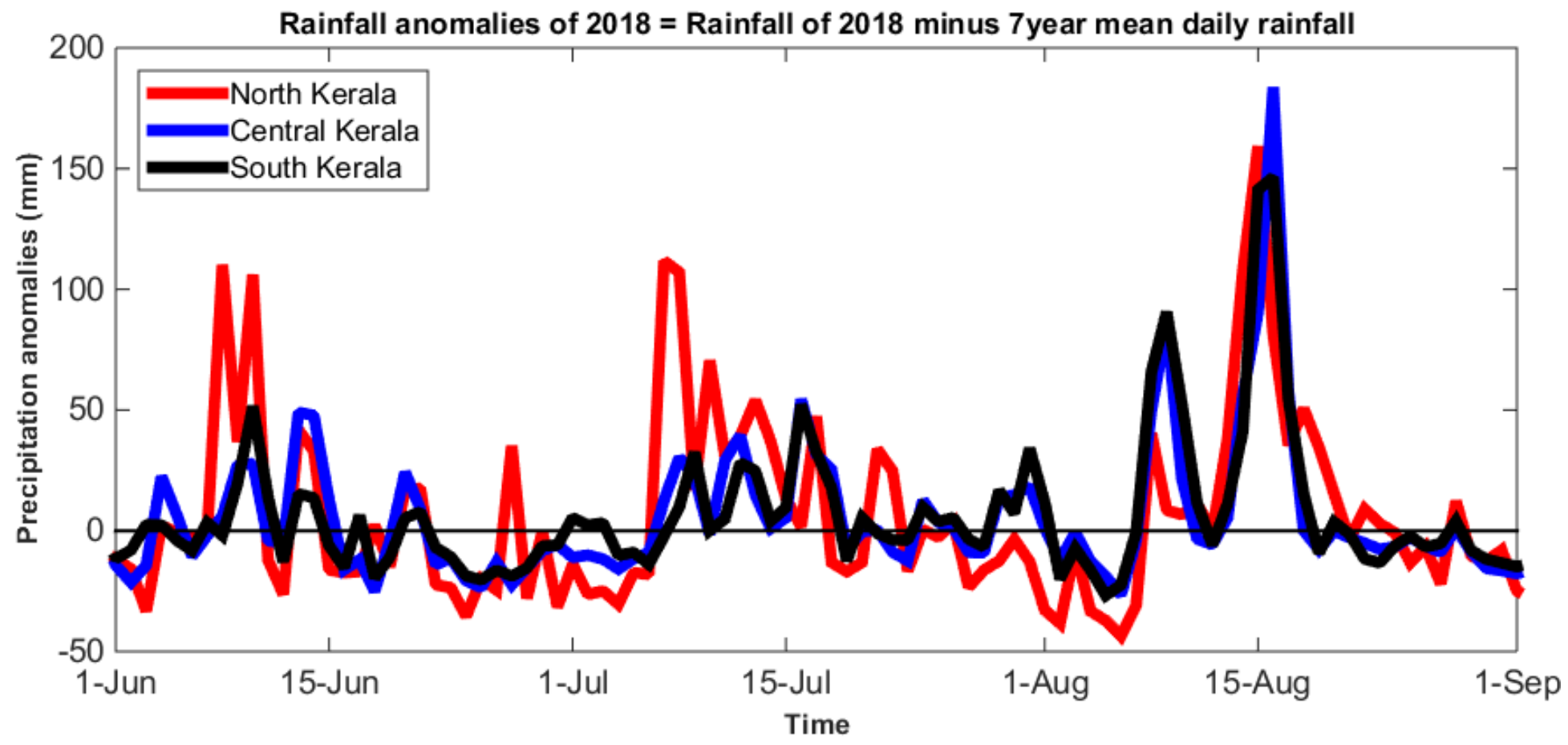

Figure 1

Fig. 1. IMD daily rainfall anomalies (in millimetres) of 2018 over North, Central and South Kerala, measured with respect to the 7 year mean precipitation.

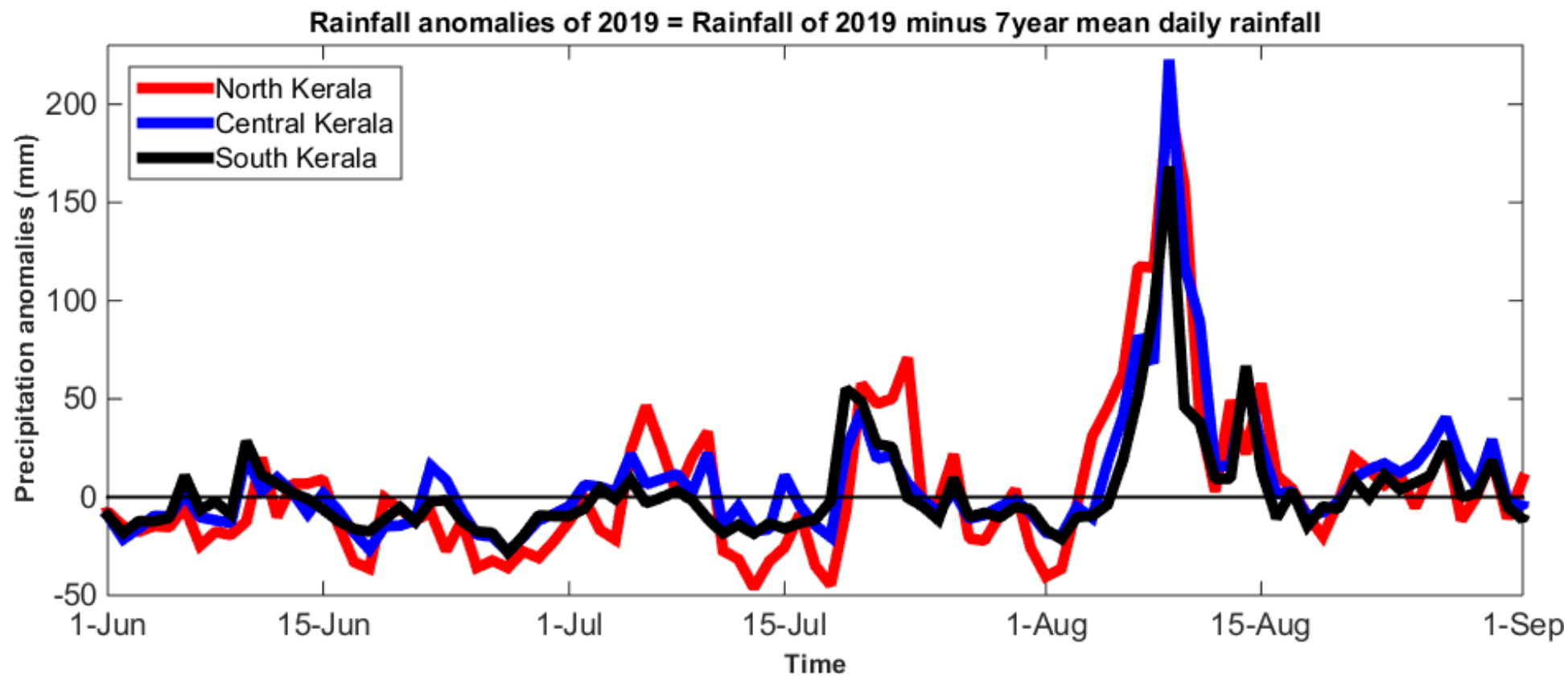

Figure 2

Fig. 2. IMD daily rainfall anomalies (in millimetres) of 2019 over North, Central and South Kerala, measured with respect to 7 year mean precipitation. 


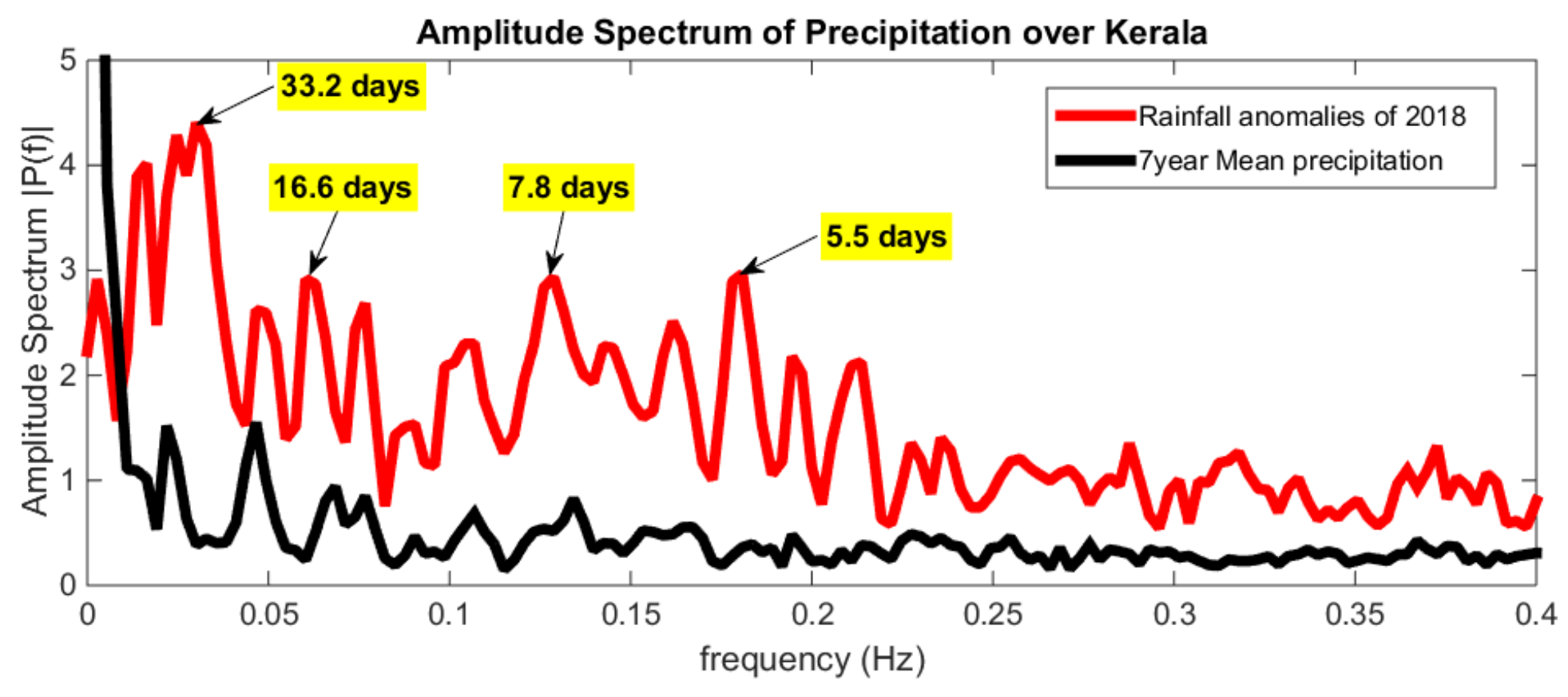

Figure 3

Fig. 3. Amplitude spectrum of IMD rainfall anomalies of 2018 averaged over the state of Kerala, in comparison to that of the 7 year mean precipitation.

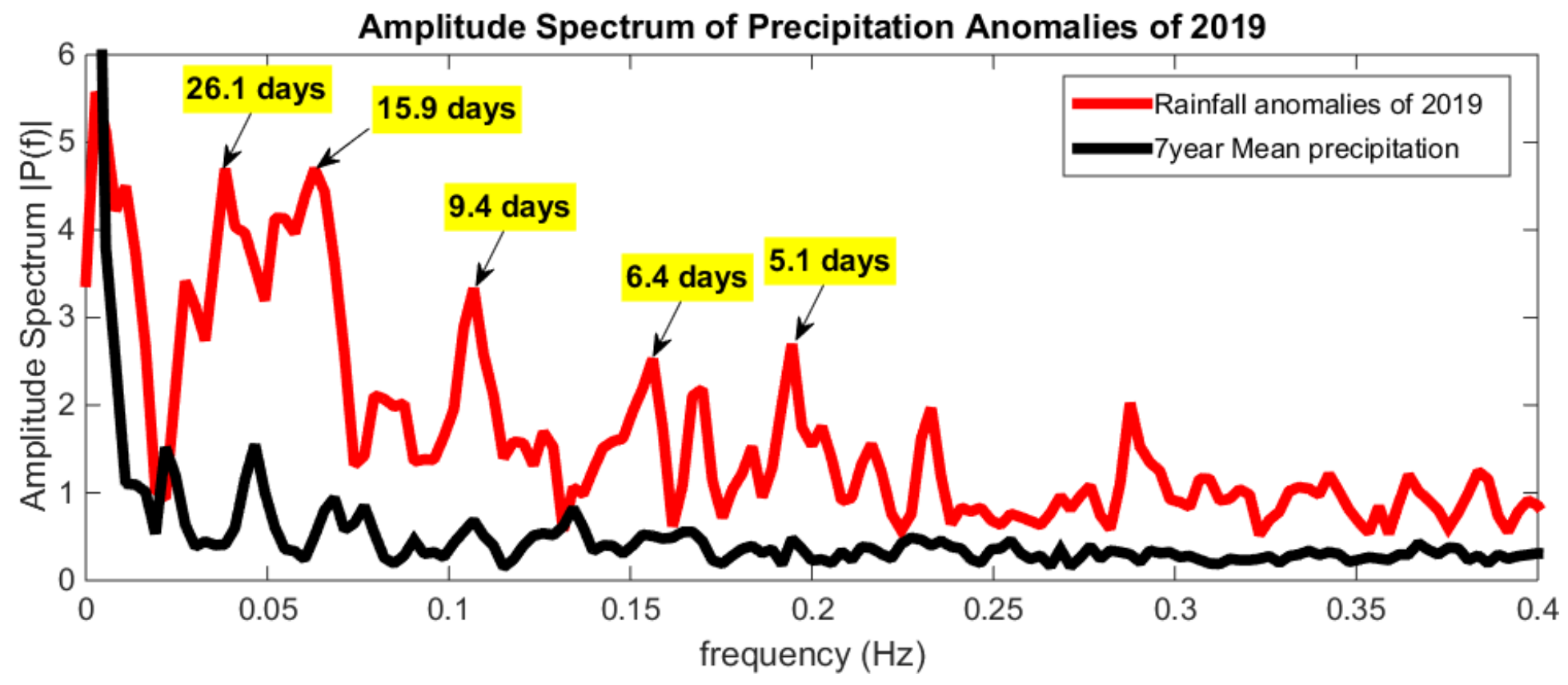

Figure 4

Fig. 4. Amplitude spectrum of IMD rainfall anomalies of 2019 averaged over the state of Kerala, in comparison to that of the 7 year mean precipitation. 


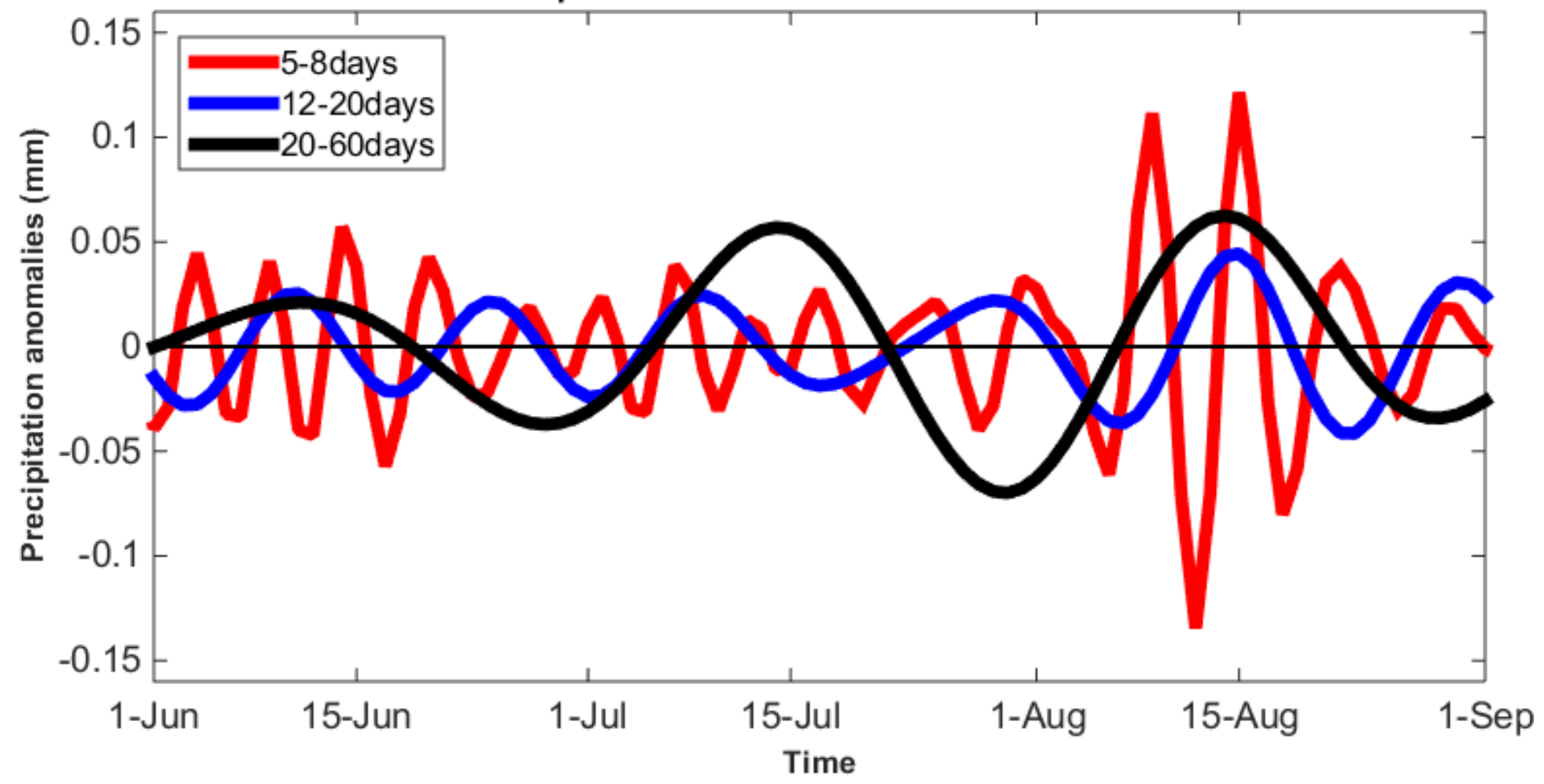

Figure 5

Fig. 5. 5-8days, 12-20days and 20-60days bandpass-filtered IMD rainfall anomalies of 2018 averaged over the state of Kerala.

\section{Bandpass-filtered rainfall anomalies of $\mathbf{2 0 1 9}$}

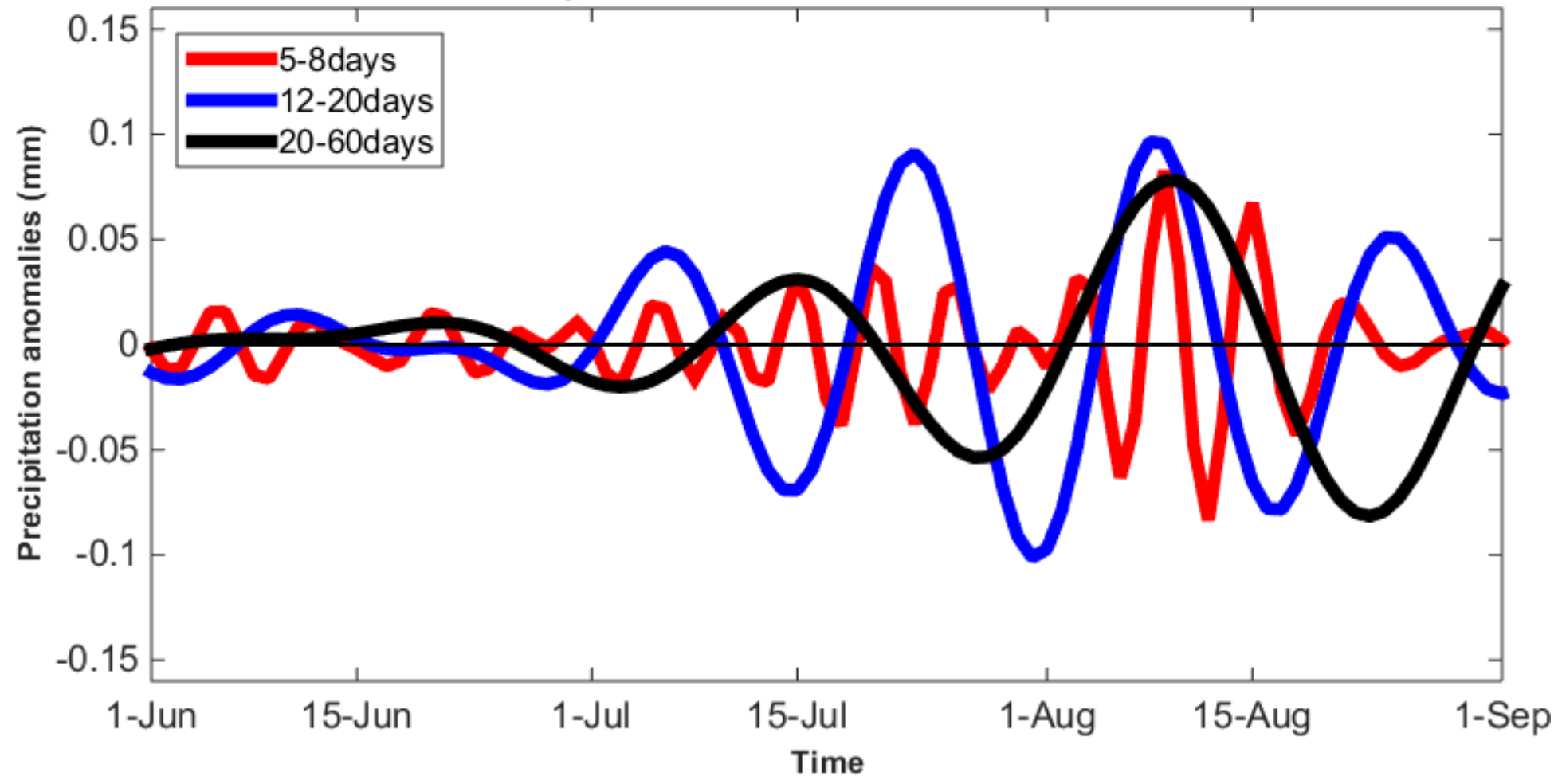

Figure 6 
Fig. 6. 5-8days, 12-20days and 20-60days bandpass-filtered IMD rainfall anomalies of 2019 averaged over the state of Kerala.

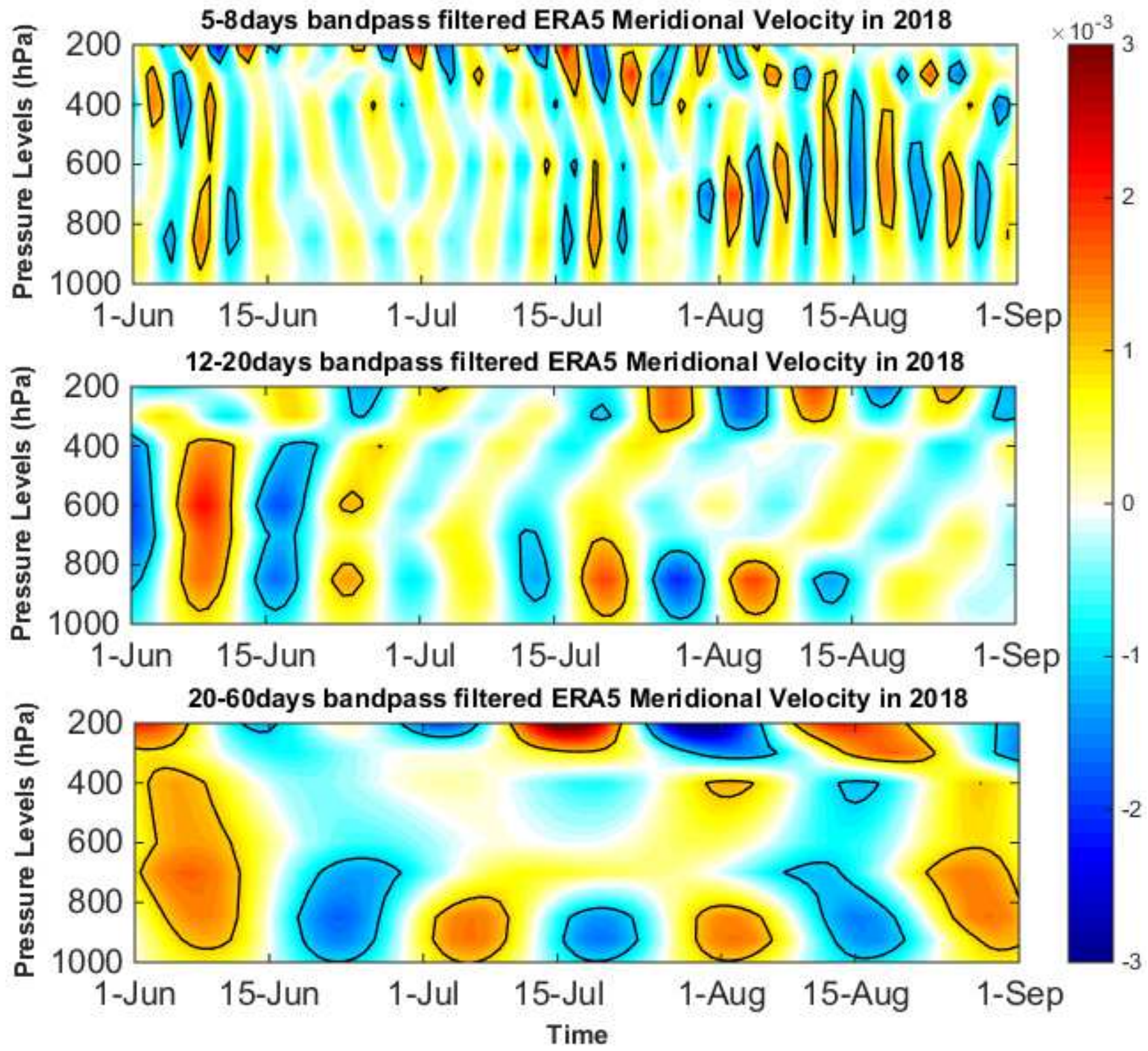

Figure 7

Fig. 7. 5-8days, 12-20days and 20-60days bandpass-filtered ERA5 Meridional velocities of 2018 averaged over the state of Kerala with altitude. 


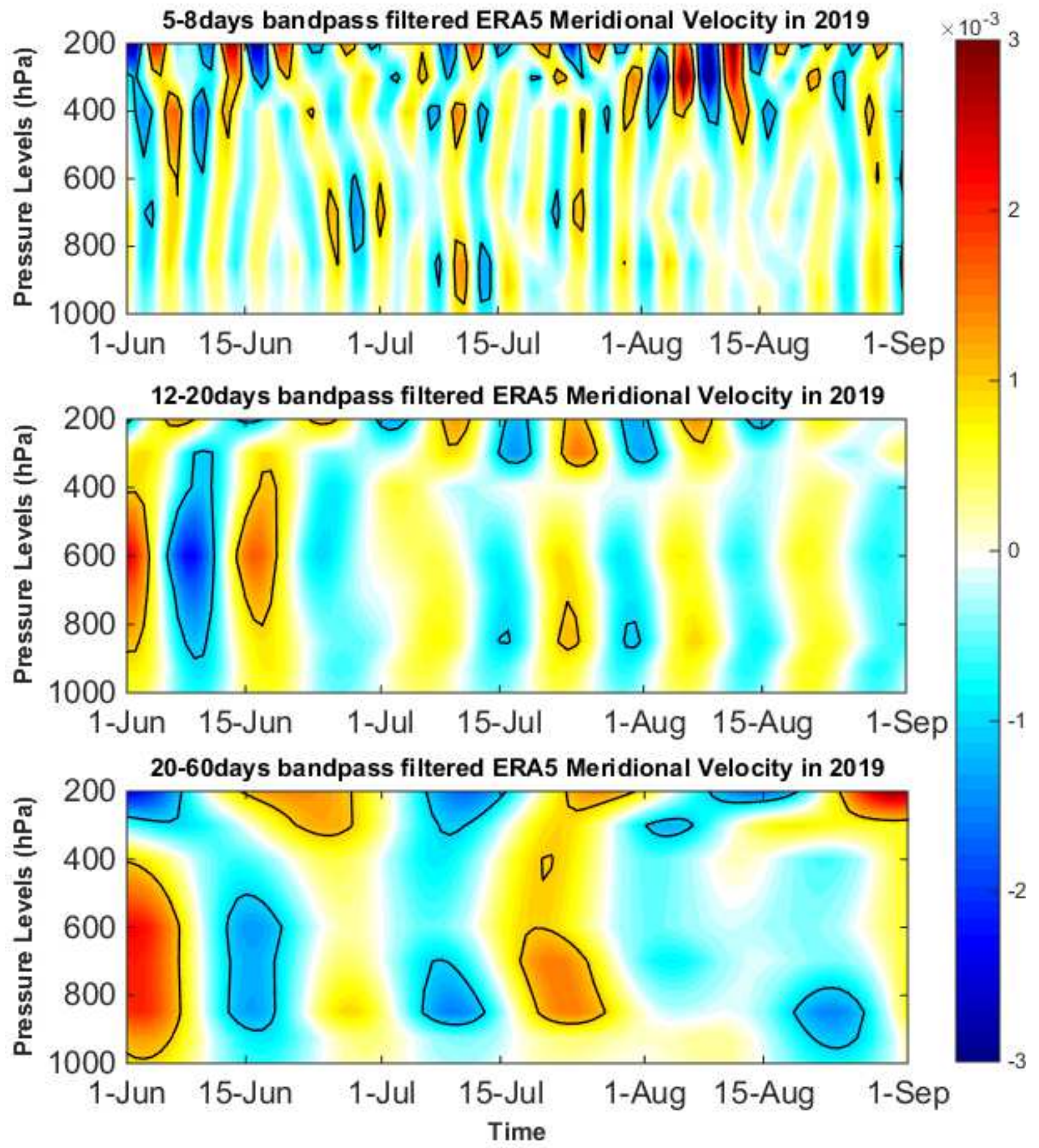

Figure 8

Fig. 8. 5-8days, 12-20days and 20-60days bandpass-filtered ERA5 Meridional velocities of 2019 averaged over the state of Kerala with altitude. 


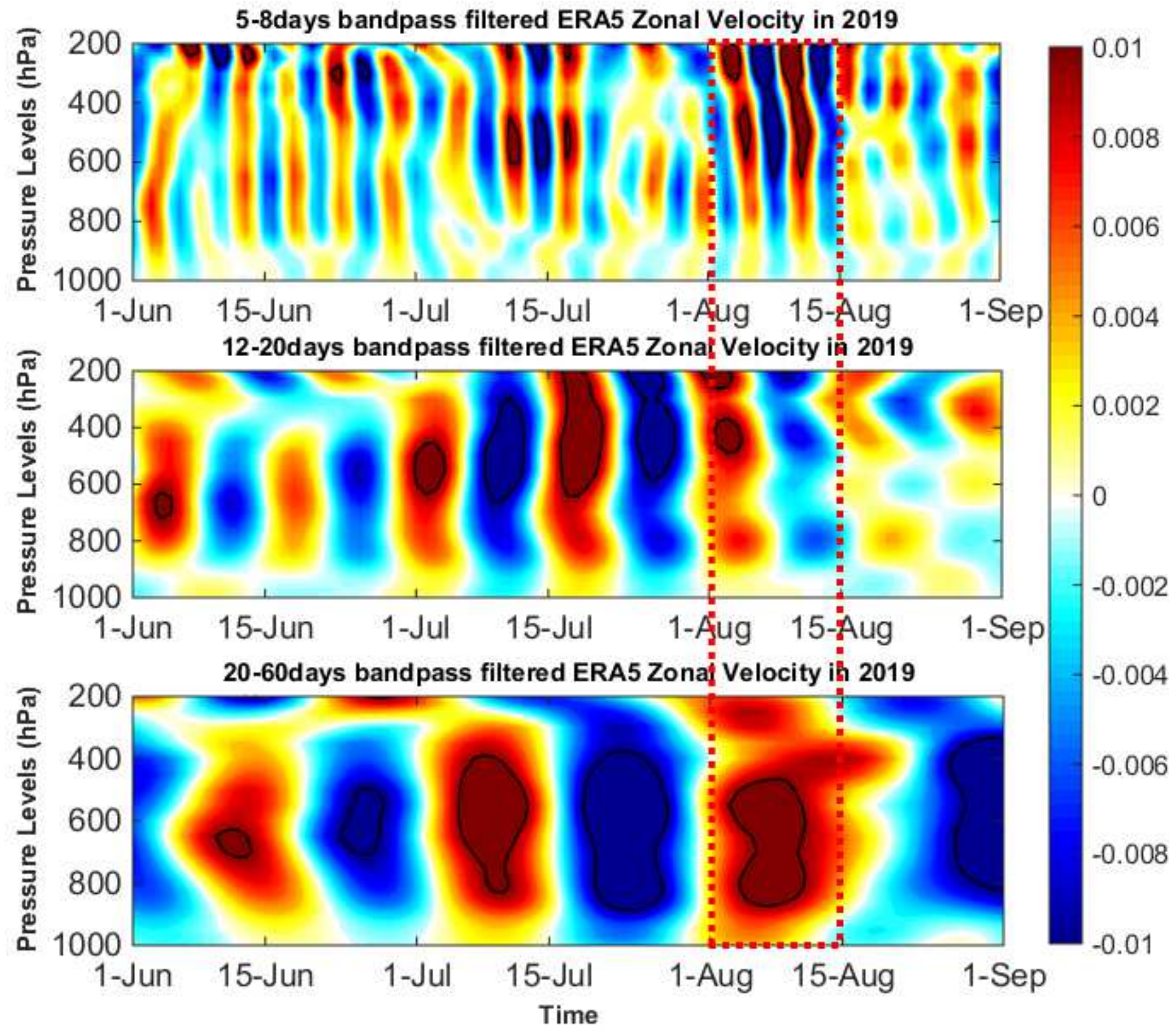

Figure 9

Fig. 9. 5-8days, 12-20days and 20-60days bandpass-filtered ERA5 Zonal velocities of 2019 averaged over the state of Kerala with altitude. The period of extreme event is shown inside the red-coloured dashed box. 

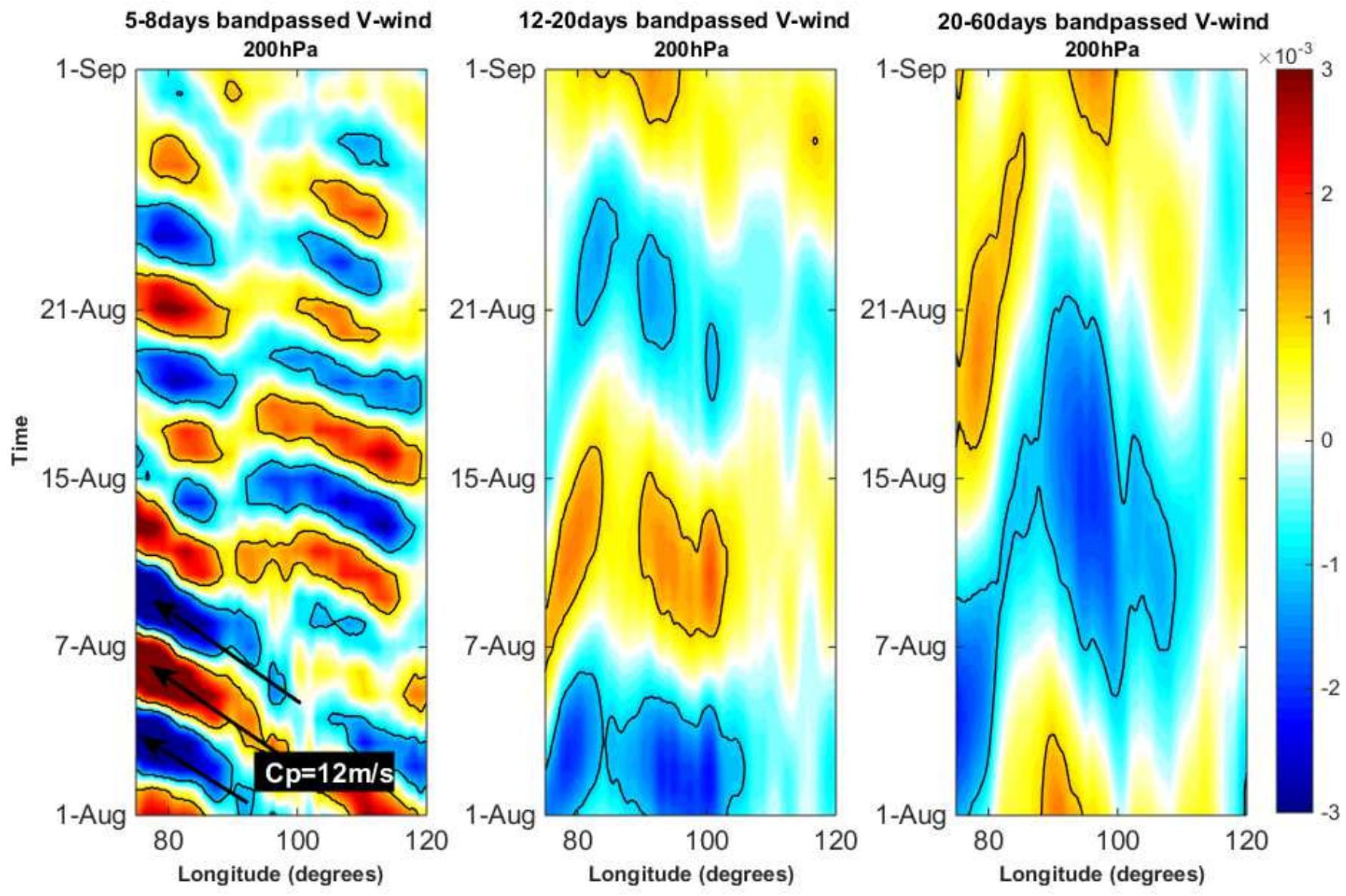

Figure 10

Fig. 11. (first figure) 5-8 days bandpass-filtered ERA5 Meridional velocities of August 2019 averaged meridionally over the state of Kerala at 200hPa pressure level. (second figure) 12-20 days bandpassfiltered Meridional velocities at $200 \mathrm{hPa}$ in 2019. (third figure) 20-60 days bandpass-filtered Meridional velocities at $200 \mathrm{hPa}$ in 2019. 

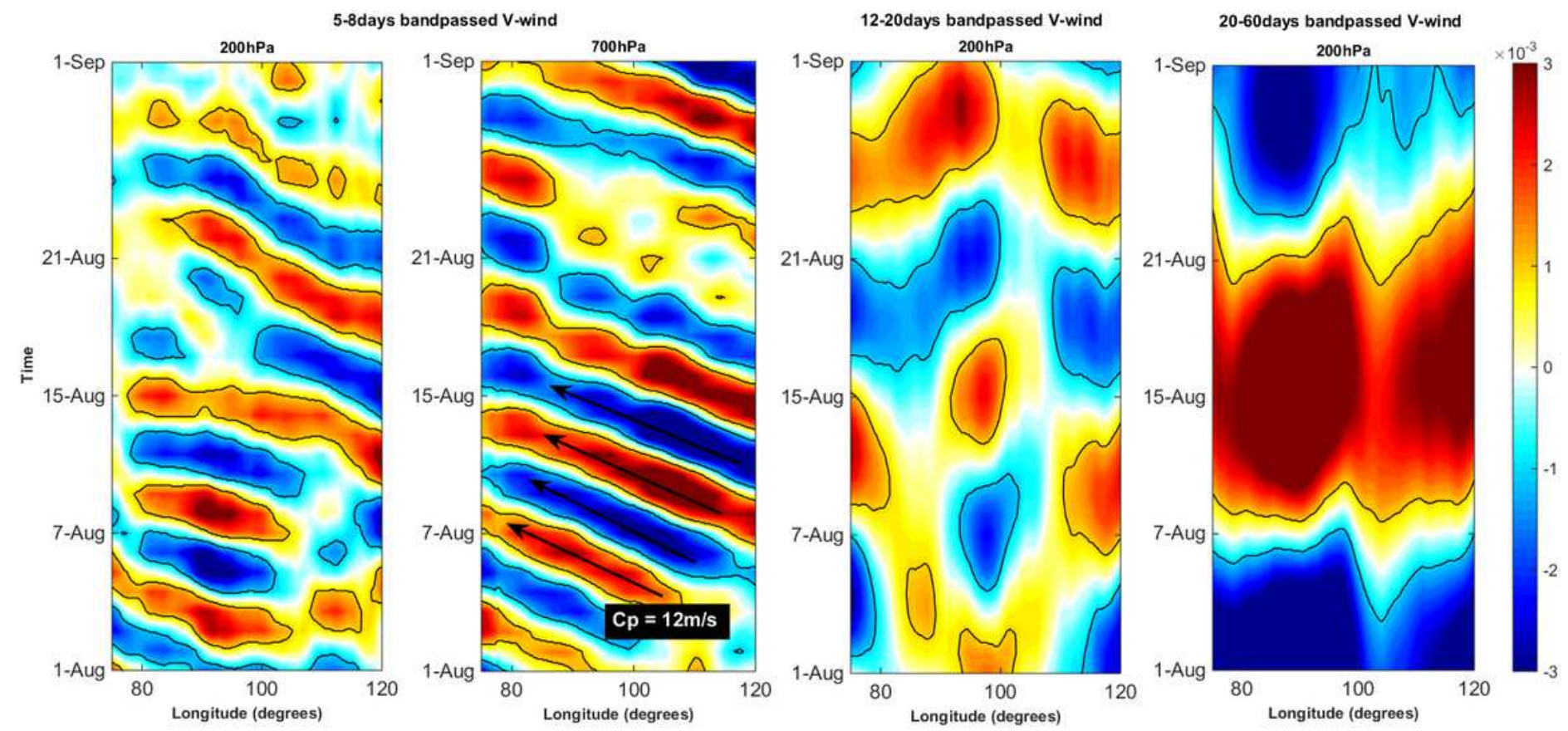

\section{Figure 11}

Fig. 10. (first \& second figure) 5-8 days bandpass-filtered ERA5 Meridional velocities of August 2018 meridionally averaged over the state of Kerala at pressure levels $200 \mathrm{hPa}$ and $700 \mathrm{hPa}$ respectively. (third figure) 12-20 days bandpass-filtered Meridional velocities at 200hPa in 2018. (fourth figure) 20-60 days bandpass-filtered Meridional velocities at 200hPa in 2018. 


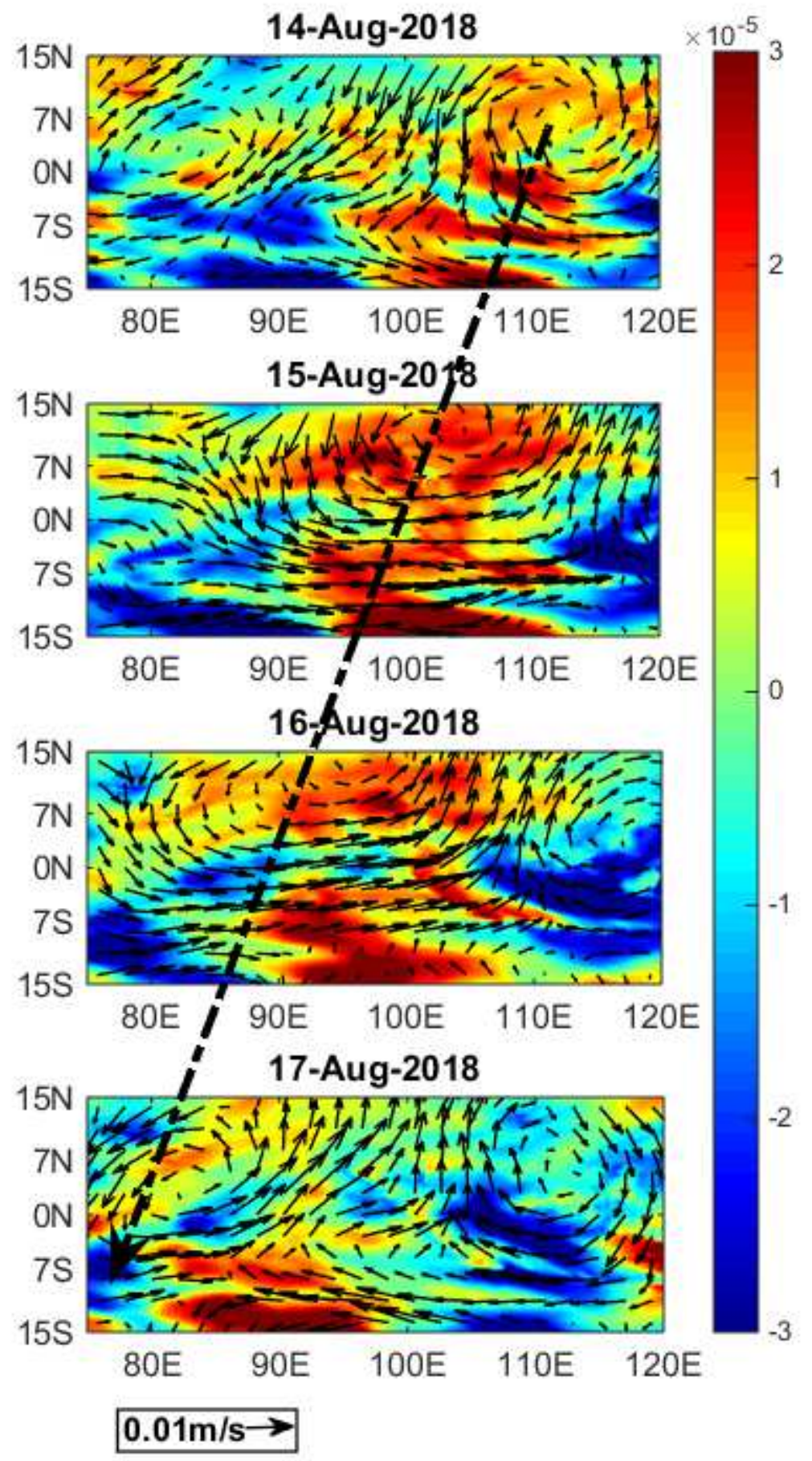

Figure 12

Fig. 12. 5-8days bandpass-filtered Specific humidity vertically integrated from surface (1000 hPa) to 600 hPa overlaid with 5-8days bandpass-filtered ERA5 winds at $700 \mathrm{hPa}$ from 14th to 17th August 2018. 